\section{Concentration and isolation of DNA from biological fluids by agarose gel isotachophoresis}

\author{
Valentina N. Kondratova, Ol'ga I. Serd'uk, Valery P. Shelepov, and \\ Anatoly V. Lichtenstein \\ Institute of Carcinogenesis, Cancer Research Centre, Moscow, Russia
}

BioTechniques 39:695-699 (November 2005)

doi $10.2144 / 000112020$

Isotachophoresis is an electrophoretic method of separation of charged substances. The method is characterized by a discontinuous buffer system, constant velocity of separated molecules, and the distribution of separated components in the form of narrow concentrated bands located one right after another. As a rule, isotachophoresis is not used for the separation of nucleic acids because the mobility of polynucleotides in this system does not depend on their size. However, this circumstance proved to be very useful for the quantitative isolation of heterogeneous DNA fragments from biological fluids, for gene diagnostics of cancer in particular. The proposed method of agarose gel isotachophoresis of DNA has been used for the isolation of blood DNA and its successful PCR analysis.

\section{INTRODUCTION}

PCR analysis of DNA isolated from blood and other biological fluids has found a variety of applications in clinical practice, in cancer $(1-4)$ and prenatal $(5,6)$ diagnostics in particular. Gene diagnostics of cancer is a new approach that has appeared at the borderline of experimental and clinical oncology-being the result of progress in fundamental research, it helps to attain some objectives of clinical oncology. The theoretical basis for gene diagnostics of cancer is the notion that carcinogenesis occurs as a result of accumulation in somatic cells of mutations in some functionally important genes. Thus, the detection of the specifically altered DNA sequences in biological fluids may indicate the presence of transformed cells in the body. Indeed, a certain amount of DNA resulting from apoptosis or necrosis of tumor cells is released into blood and urine (2,7-9). An active excretion of DNA into the surrounding medium by proliferating cells is also possible $(10,11)$. Therefore, the detection of specific mutant alleles in biological fluids of the body suggests the presence of transformed cells in the body, and this circumstance can be useful for diagnostics, monitoring, and screening for cancer (9). diagnostics of cancer is hampered by some technical problems, such as low concentration and fragmentation of DNA in biological fluids $(12,13)$. No currently available method of DNA isolation has been proven to be successful with fragmented DNA from biological fluids of the body. The existing techniques are mainly targeted at isolating high molecular weight DNA from cells and tissues and have not usually been intended for such specific cases. For instance, the widely used sorption of DNA on glass milk from chaotropic solutions is only suitable for a relatively narrow range of molecular weights (large molecules become irreversibly bound while small fragments do not bind at all), and precipitation of DNA with ethanol can result in the loss of small fragments.

Isotachophoresis (ITP) is a method of electrophoretic separation of charged molecules in which the separated components all move at a constant velocity $(14,15)$. ITP is effective for the
The wide application of gene separation and analysis of proteins on cellulose membranes (16) and is characterized by the following features: (i) a discontinuous buffer system that consists of a common cation and different anions (a fast, leading anion in the anode buffer and a slow, trailing anion in the cathode buffer) and (ii) the separated substances move in a relatively narrow zone as concentrated bands positioned one after another (17). The bands are located in the order of decreasing electrophoretic mobility in the interval between the mobilities of the leading and trailing anions.

A special modification of this method, counterflow ITP of proteins on porous membranes (made of cellulose acetate or nitrocellulose), developed by Abelev and co-workers $(16,17)$, introduces the electroosmotic flow of liquid in the direction opposite to that of protein movement. At a certain stage of the process, the counterflows equilibrate each other, and the moving boundaries of the leading and trailing anions stop, together with the protein separation zone. The theory of counterflow ITP and its practical applications have been previously described in a number of publications $(16,17)$.

Counterflow ITP of proteins has certain important advantages: it offers high resolution, multiple functionality, and the ability to carry out multistage reactions; it can easily be automated (the separation attained is preserved for any duration of the process); and the applied sample volume can be relatively large. This latter feature is particularly valuable for the analysis of biological fluids, including those with low protein content (urine, spinal, and amniotic fluids, saliva, tears, etc.).

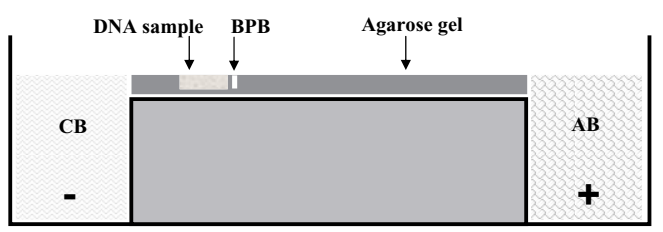

Figure 1. ITP of DNA in agarose gel (a cross-section of the electrophoresis chamber). $\mathrm{CB}$, cathode buffer (12 $\mathrm{mM}$ Tris- $\beta$-alanine, $\mathrm{pH} 8.6)$; $\mathrm{AB}$, anode buffer $(60 \mathrm{mM}$ Tris- $\mathrm{HCl}, \mathrm{pH}$ 7.6). Agarose gel dimensions are $120 \times 110$ $\times 7 \mathrm{~mm}$. Position of bromphenol blue used as a marker pointing to the border of leading and trailing anions is shown. ITP, isotachophoresis; BPB, bromphenol blue. 
As far as we know, ITP and counterflow ITP have not been used to study nucleic acids because heterogeneous polynucleotides cannot be separated by these methods. This is due to the fact that the charge of phosphate groups is distributed uniformly along the length of the molecule, and thus the electrophoretic mobility in aqueous media does not depend on molecule size. In other words, all polynucleotides present in the solution should come together into one band between the moving boundaries of the leading and trailing anions. This property, which rules out the use of ITP and counterflow ITP in most DNA studies, may prove useful in one special case, for the isolation of heterogeneous DNA fragments from biological fluids with the aim, for example, of assaying for tumor markers.

In view of the above-mentioned technical obstacles in searching for DNA markers in biological fluids, we attempted to use ITP or counterflow ITP as a simple means for concentrating and isolating DNA from human blood. Two versions of this approach were tested: $(i)$ counterflow ITP on porous membranes $(16,17)$ and (ii) ITP in a low melting point agarose gel (the counterflow due to electroosmotic forces is negligible in this case).

\section{MATERIALS AND METHODS}

\section{Blood Samples}

Blood samples $(5 \mathrm{~mL})$ from healthy donors and from patients with pancreatic cancer were obtained with informed consent from the Cancer Research Center (Moscow, Russia). Samples were drawn from a peripheral vein in native (serum) and EDTAcontaining (plasma) tubes. Blood samples were subjected to centrifugation at $1500 \times g$ for $10 \mathrm{~min}$ at room temperature. Serum and plasma aliquots were stored at $-60^{\circ} \mathrm{C}$.

\section{Counterflow ITP of DNA on a Porous Membrane}

A strip of cellulose acetate membrane or nitrocellulose membrane was soaked in anode buffer (60
$\mathrm{mM}$ Tris- $\mathrm{HCl}, \mathrm{pH}$ 7.6) containing bromphenol blue (Sigma, St. Louis, MO, USA) as a marker, and a fold (pocket) was formed in it. Into this pocket, $1-5 \mu \mathrm{g}$ salmon sperm DNA (Sigma) were added in approximately $300 \mu \mathrm{L}$ of TE buffer $(10 \mathrm{mM}$ Tris-HCl, $1 \mathrm{mM}$ EDTA, $\mathrm{pH}$ 8.6). The cathode buffer was $12 \mathrm{mM}$ Tris- $\beta$-alanine, $\mathrm{pH}$ 8.6. Electrophoresis was run for $2 \mathrm{~h}$ at $200 \mathrm{~V}$.

\section{ITP of DNA in Agarose Gel}

Low melting point agarose with low electroosmotic properties (UltraPURETM LMP agarose; Invitrogen, Carlsbad, CA, USA) and anode buffer $(60 \mathrm{mM}$ Tris-HCl, $\mathrm{pH}$ 7.6) containing $0.5 \mu \mathrm{g} / \mathrm{mL}$ ethidium bromide were used to prepare $1 \%$ gels $(120 \times 110 \times 7 \mathrm{~mm})$.

Human blood plasma or serum (100-300 $\mu \mathrm{L}$ ) was deproteinized with $50 \mu \mathrm{g} / \mathrm{mL}$ proteinase $\mathrm{K}, 0.5 \%$ sodium dodecyl sulfate (SDS; for $16 \mathrm{~h}$ at $50^{\circ} \mathrm{C}$ ) and loaded into the gel wells. The anode

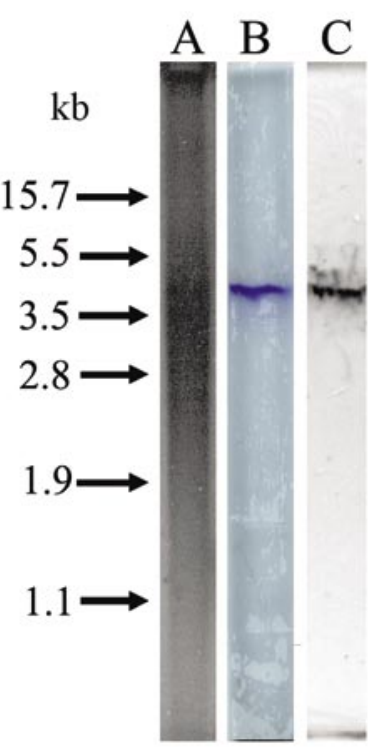

Figure 2. Counterflow ITP of heterogeneous DNA on a porous membrane. (A) Standard electrophoresis (in homogeneous field) of $5 \mu \mathrm{g}$ salmon sperm DNA in 1\% agarose gel, which is shown for comparison. The arrows on the left indicate marker positions. (B and C) Counterflow ITP $(3 \mathrm{~h}, 200 \mathrm{~V})$ of $5 \mu \mathrm{g}$ salmon sperm DNA on a cellulose acetate membrane; counterflow ITP does concentrate both bromphenol blue, (B) used as a marker, and (C) DNA. DNA was visualized by means of a transfer from the membrane to an agarose gel containing ethidium bromide (reverse Southern). ITP, isotachophoresis. and cathode tanks were filled with the respective buffers $(60 \mathrm{mM}$ Tris- $\mathrm{HCl}$, $\mathrm{pH} 7.6$, and $12 \mathrm{mM}$ Tris- $\beta$-alanine, $\mathrm{pH}$ 8.6) level with the gel surface (not higher) to avoid the mixing of the buffers (Figure 1). DNA migration was monitored during the run $(60-100 \mathrm{~V}$, 20-30 min at room temperature) by irradiating the gel with a UV source.

After the run, the DNA band stained with ethidium bromide was accurately excised from the gel, placed into an Eppendorf ${ }^{\circledR}$ tube (Eppendorf AG, Hamburg, Germany) and, after a cycle of freezing-thawing, was stored at $-20^{\circ} \mathrm{C}$. Right before the analysis, the gel was heated for $10 \mathrm{~min}$ at $95^{\circ} \mathrm{C}$ to inactivate the possible traces of proteinase $\mathrm{K}$, diluted two-fold with TE, brought to $0.1 \mathrm{M} \mathrm{KCl}$ using $0.5 \mathrm{M}$ stock, and used in PCR. In some cases, the DNA was electroeluted from the gel into a dialysis bag.

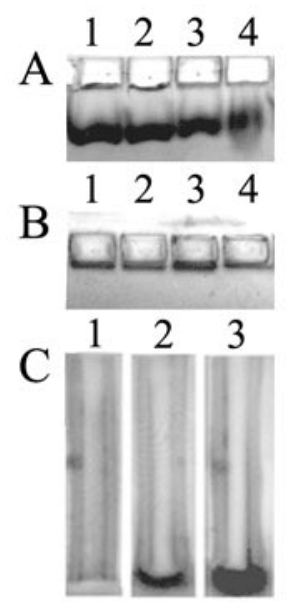

Figure 3. ITP of blood DNA in agarose gel. (A) Samples of serum (lanes 1 and 2) and plasma (lanes 3 and 4) from healthy donors were treated with proteinase $\mathrm{K}$-SDS, and $200 \mu \mathrm{L}$ aliquots were applied into agarose gel wells and subjected to standard homogeneous field electrophoresis (1\% low melting point, low osmotic agarose, 100 $\mathrm{V}$, for $20 \mathrm{~min}$ at room temperature). (B) Two hundred microliters of samples of serum (lanes 1 and 2) and plasma (lanes 3 and 4) treated as indicated above were subjected to ITP under the same conditions. (C) Three hundred microliters of samples of standard saline solution used as a control (lane 1), blood plasma (lane 2), and serum (lane 3) treated as described above were applied to the inserts (silicone tubing $5 \mathrm{~mm}$ in diameter and 30 $\mathrm{mm}$ in length cut lengthwise) and subjected to ITP in agarose gel. Electrophoresis was run at 60 $\mathrm{V}$ for $20 \mathrm{~min}$ at room temperature. SDS, sodium dodecyl sulfate; ITP, isotachophoresis. 


\section{Standard and Enriched PCR}

PCR was carried out with a Mastercycler ${ }^{\circledR} \quad$ Gradient system (Eppendorf AG) used at maximal ramp speed to amplify the following fragments: ( $i$ ) a 137-bp TP53 gene fragment including the polymorphic codon 72 (sense: 5'-TGGATGATTTGATGCTGT-3'; antisense: 5'-AGGGGCCGCGGGTGTA-3') for 35 cycles; (ii) a 157-bp K-RAS2 protooncogene fragment including the frequently mutating codon 12 (sense: 5'-ACTGAATATAAACTTGTGGTAGTTGGACCT-3'; antisense, 5'-TCAAAGAATGGTCCTGCACC$3^{\prime}$ ) for 35 cycles; (iii) a short 87-bp $K-R A S 2$ fragment also including codon 12 (sense: $5^{\prime}$-ACTGAATATAAACTTGTGGTAGTTGGACCT-3'; antisense, 5' - G T C C AC A A A AT G AT TC TGAATTAGC-3') for 35 cycles. The sequences were amplified in $25-\mu \mathrm{L}$ reactions containing $5 \mu \mathrm{L}$ DNA

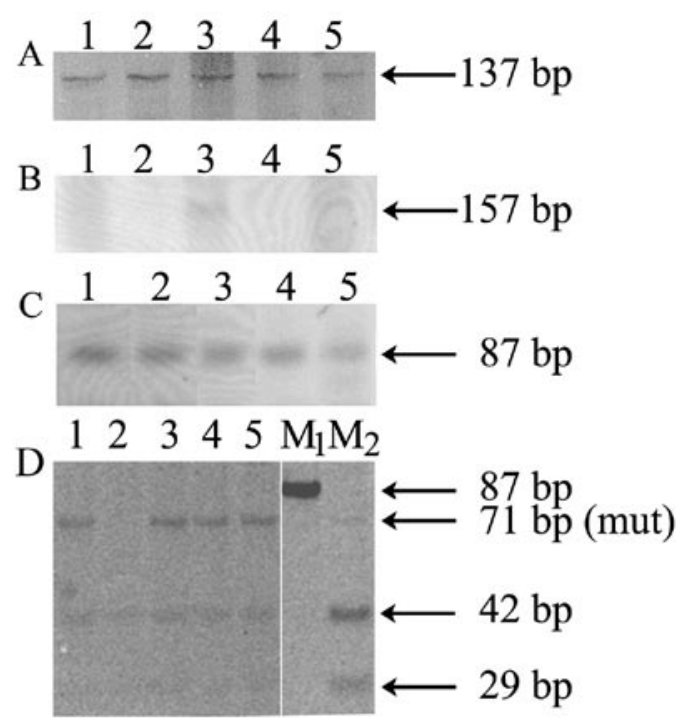

Figure 4. PCR with plasma DNA isolated by ITP in agarose gel. (A-C, lanes 1-5) Plasma DNA from healthy donors and from patients with pancreatic cancer (panel D, lanes 1-5) were isolated by the ITP in agarose gel equipped with silicon inserts as in Figure 3C. Gel slices were carefully excised, then melted and subjected to freezing-thawing, diluted two-fold with TE buffer (Tris-EDTA), and $5 \mu \mathrm{L}$ aliquots were used to run PCR. (A) Amplification of a 137-bp fragment of the TP53 suppressor gene; (B) amplification of a 157-bp fragment of the $K-R A S 2$ protooncogene; and (C) amplification of an 87-bp fragment of the $K-R A S 2$ protooncogene. (D) Plasma DNA samples from patients with pancreatic cancer (lanes 1-5) were subjected to enriched PCR (PCR product size of $87 \mathrm{bp}$ ) to reveal probable mutant K-RAS2 sequences (codon 12). The 71-bp band is indicative of the mutation (mut; see text). M1 and M2, markers indicating the positions of the K-RAS2 PCR product, intact and treated, respectively, with endonuclease BstNI. ITP, isotachophoresis. samples, 5 pmol of each primer (Syntol, Moscow, Russia), $200 \mu \mathrm{M}$ $16.6 \mathrm{mM}\left(\mathrm{NH}_{4}\right)_{2} \mathrm{SO}_{4}, 2 \mathrm{mM} \mathrm{MgCl}$, $2^{\circ} \mathrm{C}$ for $20 \mathrm{~s}$.

Enriched PCR was used to detect mutant K-RAS2 (codon 12) by a two-stage procedure using selective restriction enzyme digestion of an artificially created $B s t \mathrm{NI}$ site to cleave $\mathrm{K}-R A S$ sequences $(1,18)$. RAS mutations in the 87-bp PCR ere detected as previously $94^{\circ} \mathrm{C}$ for $30 \mathrm{~s}, 58^{\circ} \mathrm{C}$ for $20 \mathrm{~s}$, and $72^{\circ} \mathrm{C}$ for $20 \mathrm{~s}$. An aliquot of $10 \mu \mathrm{L}$ adjusted to $1 \times B s t$ NI reaction buffer was digested U of BstNI (MBI Fermentas, Moscow, Russia) at $60^{\circ} \mathrm{C}$ for $90 \mathrm{~min}$. Ten microliters of the digested PCR mixture were transferred to a new tube, and a new reaction mixture was set up for the second amplification step (38 cycles at $94^{\circ} \mathrm{C}$ for $30 \mathrm{~s}, 58^{\circ} \mathrm{C}$ for $20 \mathrm{~s}$, and $72^{\circ} \mathrm{C}$ for $20 \mathrm{~s}$ ). The second BstNI digestion was performed using $25 \mu \mathrm{L}$ of the second-step PCR product at $60^{\circ} \mathrm{C}$ for $90 \mathrm{~min}$. The amplification products were separated by $10 \%$ polyacrylamide gel electrophoresis (PAGE). The nonrestricted PCR product is $87 \mathrm{bp}$ long, while cleavage at both sites (wild-type sequence) creates a 42-bp fragment, and cleavage only at the $3^{\prime}$ site (the $5^{\prime}$ site is modified by the mutation) yields a 71-bp fragment.

\section{RESULTS AND DISCUSSION}

In preliminary experiments, we have found that counterflow ITP on a porous membrane indeed brings together different DNA fragments to form a narrow band that co-migrates with the bromphenol blue dye (Figure 2). This observation seemed to meet our objectives, but the approach appeared to be inconvenient. First, it was difficult to visualize the DNA on the membrane in order to assess its quantity and elute it: ethidium bromide and $\mathrm{SYBR}^{\circledR}$ Gold tightly bind to the membrane and create a high background. Second, visualization of DNA directly on the membrane requires a prior fixation of the molecules (by drying or UV irradiation), thus preventing its subsequent elution from the membrane. Finally, the transfer of DNA from the membrane to an agarose gel stained with ethidium bromide (reverse Southern), which we have employed for DNA visualization, shows the counterflow ITP capabilities (Figure 2) but does not solve the practical problem of DNA isolation.

As an alternative to porous membranes, we have tried ITP of DNA in agarose gels (Figure 1). In the case of low osmotic agarose gel, the counterflow due to electroosmotic force is negligible. The drawbacks of this technique, namely the deformation of the gel in a nonhomogeneous electric field, are well known (20). Indeed, when the process occurs long enough, the gel becomes deformed and the separation area distorted (data not shown). However, it was possible to use the method for concentrating DNA in low melting point agarose with low electroosmotic properties because the process took only $20-30 \mathrm{~min}$. ITP of deproteinized serum (or plasma) in an agarose gel resulted in the formation of a concentrated DNA band right at the front edge of the well (Figure 3B), whereas in conventional electrophoresis (i.e., in a homogeneous electric field), the DNA band is quite fuzzy, probably due to the heterogeneity of the DNA and diffusion of small fragments (Figure 3A).

As is shown on Figure 3B, DNA forms a sharp band during ITP. To increase DNA concentration maximally, it is desirable to make the band as narrow as possible. This consideration determines the dimensions of the well to which DNA is applied. Apparently, using equal volumes of DNA sample, the more narrow (and, correspondingly, the longer) the well, the higher 
the DNA concentration in the agarose slice that can be attained. However, making long and narrow wells has the drawback that small DNA molecules diffuse from solution into the agarose and form long "tails" during the run where much of the material is lost. To prevent diffusion into the sides, we employed inserts made of silicon tubing, $30 \mathrm{~mm}$ long, $5 \mathrm{~mm}$ in diameter, and cut lengthwise, which were put into agarose wells of similar size and fixed with melted agarose. Blood plasma and serum (about $300 \mu \mathrm{L}$ ) treated with proteinase K-SDS and containing 0.5 $\mu \mathrm{g} / \mathrm{mL}$ ethidium bromide were applied into the silicon inserts, and electrophoresis of DNA under visual inspection by UV irradiation was performed (for $20 \mathrm{~min}$ at $60 \mathrm{~V}$ and room temperature). The DNA migrated from the insert into the gel edge and was concentrated in a small piece of agarose (Figure 3C).

The ability of ITP to concentrate DNA opens up an opportunity to use this method as a relatively simple means for isolating and purifying heterogeneous DNA from biological fluids for subsequent analysis. We were able to use small quantities of plasma from healthy donors for successful PCR amplification of the TP53 suppressor gene and $K-R A S 2$ protooncogene, which are most often used for cancer gene diagnostics (Figure 4, A-C). It is noteworthy that the PCR signal was weaker in cases of a larger PCR product (the 157-bp fragment was not seen in all cases). This observation is in agreement with the literature (13) and suggests a significant fragmentation of DNA in biological fluids.

Mutations of the K-RAS2 gene (usually confined to codon 12) are often found in colorectal and pancreatic cancer as well as in circulating DNA in patients with these pathologies $(1,3,4,9,11,12)$. We tested our method of DNA isolation by the detection of $\mathrm{K}-R A S 2$ gene mutations in circulating DNA from patients with pancreatic cancer. Enriched PCR, which is based on the introduction of artificial restriction sites and employs a two-stage procedure with a selective removal of only wild-type sequences between two steps $(18,19)$, was used for the analysis of isolated DNA. The band of $71 \mathrm{bp}$, indicating a codon
12 mutation, was found in 4 out of 5 samples tested (Figure 4D).

Thus, our data indicate that ITP in agarose gel can be effectively employed for diagnostic purposes. This technique does not require special equipment, allows quantitative isolation of DNA, and is simple and rapid. Another advantage is the ability to visually monitor the DNA band formation during the run as well as its amount because nucleic acid content in human blood may vary greatly. Finally, in view of the high flexibility of ITP $(21,22)$, one may suppose that the method can be further improved and adapted to various new tasks.

\section{ACKNOWLEDGMENTS}

This work was supported by the Russian Foundation for Basic Research (grant no. 04-04-48094 to A.V.L.).

\section{COMPETING INTERESTS STATEMENT}

The authors declare no competing interests.

\section{REFERENCES}

1.Kopreski, M.S., F.A. Benko, C. Kwee, K.E. Leitzel, E. Eskander, A. Lipton, and C.D. Gocke. 1997. Detection of mutant K-ras DNA in plasma or serum of patients with colorectal cancer. Br. J. Cancer 76:1293-1299.

2.Botezatu, I., O. Serdyuk, G. Potapova, V. Shelepov, R. Alechina, Y. Molyaka, V. Anan'ev, I. Bazin, et al. 2000. Genetic analysis of DNA excreted in urine: a new approach for detecting specific genomic DNA sequences from cells dying in an organism. Clin. Chem. 46:1078-1084.

3.Johnson, P.J. and Y.M. Lo. 2002. Plasma nucleic acids in the diagnosis and management of malignant disease. Clin. Chem. 48:11861193.

4.Anker, P., H. Mulcahy, and M. Stroun. 2003. Circulating nucleic acids in plasma and serum as a noninvasive investigation for cancer: time for large-scale clinical studies? Int. J. Cancer 103:149-152.

5.Chiu, R.W., T.K. Lau, P.T. Cheung, Z.Q. Gong, T.N. Leung, and Y.M. Lo. 2002. Noninvasive prenatal exclusion of congenital adrenal hyperplasia by maternal plasma analysis: a feasibility study. Clin. Chem. 48:778780.

6.Poon, L.L., T.N. Leung, T.K. Lau, K.C. Chow, and Y.M. Lo. 2002. Differential DNA methylation between fetus and mother as a strategy for detecting fetal DNA in maternal plasma. Clin. Chem. 48:35-41.

7.Chen, X.Q., M. Stroun, J.L. Magnenat, L.P. Nicod, A.M. Kurt, J. Lyautey, C. Lederrey, and P. Anker. 1996. Microsatellite alterations in plasma DNA of small cell lung cancer patients. Nat. Med. 2:1033-1035.

8.Nawroz, H., W. Koch, P. Anker, M. Stroun, and D. Sidransky. 1996. Microsatellite alterations in serum DNA of head and neck cancer patients. Nat. Med. 2:1035-1037.

9.Sidransky, D. 2002. Emerging molecular markers of cancer. Nat. Rev. Cancer 2:210219.

10.Anker, P., J. Lyautey, C. Lederrey, and M. Stroun. 2001. Circulating nucleic acids in plasma or serum. Clin. Chim. Acta 313:143146

11.Stroun, M., J. Lyautey, C. Lederrey, A. Olson-Sand, and P. Anker. 2001. About the possible origin and mechanism of circulating DNA apoptosis and active DNA release. Clin. Chim. Acta 313:139-142.

12.Lichtenstein, A.V. and G.I. Potapova. 2003. Genetic defects as markers of tumor development. Mol. Biol. (Mosk.) 37:181-193.

13.Su, Y.H., M. Wang, D.E. Brenner, A. Ng, H. Melkonyan, S. Umansky, S. Syngal, and T.M. Block. 2004. Human urine contains small, 150 to 250 nucleotide-sized, soluble DNA derived from the circulation and may be useful in the detection of colorectal cancer. J. Mol. Diagn. 6:101-107.

14.Beckers, J.L. and F.M. Everaerts. 1972. The separation of nucleotides by isotachophoresis J. Chromatogr. 71:380-385.

15.Everaerts, F.M., J.L. Beckers, and T.P. Verheggen. 1973. Some theoretical and practical aspects of isotachophoretical analysis. Ann. N.Y. Acad. Sci. 209:419-444.

16.Abelev, G.I. and E.R. Karamova. 1984 Counterflow immunoisotachophoresis on cellulose acetate membranes. Anal. Biochem. 142:437-444

17.Abelev, G.I. and E.R. Karamova. 1996 Automation on membranes: countercurrent isotachophoresis and immunoelectrochromatography. Biokhimiia 61:1984-1994.

18.Kahn, S.M., W. Jiang, T.A. Culbertson, I.B. Weinstein, G.M. Williams, N. Tomita, and Z. Ronai. 1991. Rapid and sensitive nonradiactive detection of mutant $\mathrm{K}$-ras genes via "enriched" PCR amplification. Oncogene 6:1079-1083

19.Su, Y.H., M. Wang, T.M. Block, O. Landt, I. Botezatu, O. Serdyuk, A. Lichtenstein, H. Melkonyan, et al. 2004. Transrenal DNA as a diagnostic tool: important technical notes. Ann. N.Y. Acad. Sci. 1022:81-89.

20.Bringard, A. and R. Charlionet. 1990 Multiphasic electrophoresis with diversified spacers. Electrophoresis 11:802-809.

21.Abelev, G.I. 1978. Immunoisotachophoresis on cellulose acetate film. Biull. Eksp. Biol. Med. (Mosk) 86:110-113.

22.Lemmens, A.A., J.C. Reijenga, F.M. Everaerts, R.T. Janssen, J.A. Hulsman, and C.A. Meijers. 1985. Isotachophoresis as a candidate reference method in analytical chemistry. Determination of sodium in serum. J. Chromatogr. 320:193-197. 
Received 13 May 2005; accepted 5 July 2005.

Address correspondence to Anatoly $V$. Lichtenstein, Head, Laboratory of Tumor Biochemistry, Institute of Carcinogenesis, Cancer Research Center, Kashirskoye shosse 24, Moscow, Russia.

e-mail:alicht@online.ru

To purchase reprints

of this article, contact

Reprints@BioTechniques.com 